\title{
Problems and Countermeasures of Mutual Pension Model in Time Bank in China against the Background of "a boom of the graying"
}

\author{
Zeng Jia, Chen Shuang \\ Business School of Hubei University \\ Wuhan 430062, China
}

\begin{abstract}
Under the impact of the "silver wave", not only the aging of Chinese is on the rise, but also the pressure on social pension is continue to increase. China's undertakings for the aged and the construction of the pension system are confronted with dire challenges. In order to cope with aging society, China has formed a pension system based on home-based care service, supported by communities and supplemented by institutions. However, the family structure has become miniaturization and centralization and the demand for pension has characterized by diversity and individuality. The single pension mode cannot satisfy the large number of elders. The Time Bank, as an emerging pension model, has certain practical significance to relieve the pressure of endowment. Based on the study of the pension dilemma in China, this paper puts forward the problems of the pension model of The Time Bank in policy, time value and social cognition and corresponding countermeasures.
\end{abstract}

Keywords-aging society; pension model; pension model of "Time Bank"

\section{INTRODUCTION}

According to the traditional standards of the UN, a region has more than 10 percent population of over 60 years old people is called aging society, while the new standard is 7 percent of people aged 65 years old. China's sixth national population census at the end of November 2010 shows that 65-year-old elderly population has up to 119 million, accounting for 8.87 percent of the total population, and the population of people aged over 60-year-old has reached 178 million, accounting for 13.26 percent of the total, which has already achieved the standard of UN. Besides, China's aging is dramatically quick and China has entered an aging society only in 18 years, resulting in the whole society and young people are facing huge pension pressure, which has drawn all walks of people's attention and serious discussion.

\section{A. The Pension Dilemma Under China's National Conditions}

Pension problem has always been a difficulty for many countries centuries. Lacking of understand of China's national conditions and shackled by conventional thinking of "raise children for retirement safeguard", Chinese elder hope their children to improve their quality of life in old age. However, this kind of pension system is no longer applicable and the lack of pension facilities and the poor quality of service and other such kind of problems in China also cannot be ignored.

\section{B. Poor Mental and Physical Condition of Elderly}

The elderly is vulnerable group in the society, with the growth of age, their immunity begins to decline gradually, their physiological functions begin to deteriorate and health problems of respiratory, digestive, cardiovascular and cerebrovascular and reproductive system continue to increase. China's 2018 blue book on aging pointed out that Chinese elderly are in a low state of health, nearly half of them never exercise and only about 30 percent of elderly are in a good health. Due to the change of their social state and health conditions, the elderly is prone to negative emotions such as pessimism and anxiety. Influenced by China's one-child policy, most elderly only have one child. A couple need to take care of four elderly (the couple's parents) and one child. They are busy with working and taking care of their child and don't have time to accompany their parents, which leads to more and more serious "empty nest" problem. What's worse, some young people live off their parents so that the material and emotional needs of Chinese elderly are far from being satisfied.

\section{Lack of Nursing Staff for Elderly}

China's large population base and rapid aging have left Chinese society unprepared for a sudden "boom of graying". And influenced by the idea of "raise children for retirement safeguard", people generally have resistance to other pension model than home-based care. Even though young children are forced to send their elder parents to the nursing home, they will be criticized by other people. To sum up, China's pension institutions are born with insufficient development, which is difficult to further develop. China's pension facilities gradually developed after 2000 and according to the report of the National Development and Reform Commission, China had about 6.698 million special beds for aged and 30.3 beds per 1000 elderly people. But there is a huge gap in professional nursing staff. The total number of disabled and semi-disabled elders will increase to 45 million by 2020 and about 36.5 million disabled and semi-disabled elders need nursing care except some elders who are in nursing institutions, according to the China's Social Security Development report. If 1 nursing staff can take care of 10 elders, there would be a huge gap of more than 3.65 million nursing staff. 


\section{Poor Quality of Pension Service}

The main pension institutions in the society are divided into public and private institutions. But some public pension institutions are face-saving projects that don't have competition crisis, crisis awareness and reward and punishment mechanism. And due to its for-profit and pressure of competition, private pension institutions attach importance to control cost rather than improve quality, which leads to poor service quality, safety awareness and social responsibility. In a word, the quality of service of both public and private pension institutions is poor.

\section{ChOICE OF CHINESE PENSION MOdEL}

Chinese pension system is confronted with many difficulties. In fact, the primary need of pension can be divided into four parts, including good health, enough money, company of family and professional care. Apart from the traditional pension system, the main pension systems of nowadays are social pension and community pension, however, both have its disadvantages.

\section{A. Social Pension}

Social pension is enforced by the government, requiring people who are in their working period to pay the basic social pension insurance whether they work in enterprises or public institutions, social pension aims to ensure the primary need of their later life. To a certain extent, this system alleviates the financial pressure on the elders. At the same time, services such as medical care and life care are provided to elders through the establishment of welfare homes for the aged and non-profit institutions for the aged. Although the elders can receive necessary care, their psychological needs are not guaranteed just like a bird in the cage, waiting to die alone. What's more, this kind of life is based on the family expenditure, which may make elders feel like a burden on their family and society since they lost their social value and their goals of their life. In order to reduce the burden on their children, they live lonely and gradually become "old orphans". Nevertheless, elders have rich social and life experience. As the saying goes: The old man is a treasure. Elders can actually bring a lot of guidance to the family and society. It's just a serious waste of social resources to arrange elders in nursing institutions to wait for death.

\section{B. 2.2 Community Pension}

In November 2011, China began implementing a comprehensive two children policy to address the crisis of social aging; in December 2013, China further implemented the one child policy; and in October 2015, the Chinese government announced an active response to the population ageing---full implementation of the two -child policy. In the past, family planning policy led to the gradual miniaturization and centralization of China's family structure, and the "421" family model became more and more common. The model of two young couples taking care of four old people and one child will happen to this generation, the pressure of young people will multiply, and the single family support will cause more social problems. Therefore, some scholars have put forward a community- based family support model to deal with this problem. The home life is matched with community care, thus not only meeting the needs of the elderly for freedom, but also achieving health protection for the elderly. This idea is very good. However, according to China's actual situation, it is difficult to achieve in the short term. China's aging rate is too fact, resulting in many Chinese old people actually "getting old before they get rich". With foreign countries into the aging of the developed countries cannot be compared, and the professional old -age community, due to all aspects to take into account the particularity of the elderly population, so the entry threshold is higher, only part of the affluent elderly can live in such a community, the average family simply cannot afford, so the family pension model cannot reach the general public.

\section{Advantages of Time Bank Pension Model}

Time Bank pension model was first introduced in the early 1980s by American Edger Kahn. This particular bank stores "time currency", which members can obtain money by providing services to others and also can withdraw money and get help from others when they in need. They can quantify their services over time to help each other through Time Bank. As of today, Time Bank has been practiced in 26 countries since its first establishment in the United States in 1990. Influenced by traditional concepts, many old people in China are reluctant to leave their original families and communities to spend their later life in a new environment. However, the emergence of the model of mutual support of Time Bank can make use of the resources in the community to realize the home-based care of elders. Compared with social pension system and traditional community pension system, Time Bank pension model has its unique advantages.

\section{A. Initiative}

During the 32nd group study of Political Bureau of the Central Committee of the Communist Party of China, President $\mathrm{Xi}$ stressed the necessity to strengthen the ideology of the whole society to actively deal with the aging population. We should take a positive view of the aging society and the elderly and their life. Being old is an important stage in one's life but one can still make progress and be happy. Effective response to the aging population will not only improve the life quality of the elderly and safeguard their dignity and rights, but also promote economic development and social harmony. The elderly is part of the society. From a negative aspect, they are the burden but also a vulnerable group of people that needs passive social help. But if we put it in a positive way, turn passivity into initiative and let the elderly seek a guarantee for themselves through their own efforts, they may feel respected and do not consider themselves as burden. And also, this can save lots of resources and labor force. For the elderly, they truly can enjoy what they earn.

\section{B. Co-ordination}

With the diversification of the needs of the elderly, the pursuit of high-quality material and rich spiritual life has become the mainstream of society. Great challenges have been brought by diverse needs that cannot be satisfied by social pension system and community pension model. However, we can better co-ordinate various resources and provide various services through the Time Bank pension platform, whose advantages cannot be replaced by other pension models. 


\section{3.3 Sustainability}

If we can establish a good platform to ensure the sustainable Time Bank operate regularly, it can continue to operate in the future. And different from the voluntary pension services that require volunteers have responsibility and love, Time Bank pension model is easy to put into practice in China and is more sustainable. Time Bank pension model has strong vitality and sustainability because of its incentive mechanism, which, to some extent, makes up for the defects of other traditional pension model. Elders can use services to store "time currency" for themselves and buy a solid "insurance" for their later years.

\section{PROBlems OF TIME BANK PENSION MODEL}

In some developed countries, time banking has benefited many elderly people. However, due to the late start, the limitations of traditional concepts and backward policies, the development of time banking is not satisfactory

\section{A. Policy Support Is Inadequate}

To do a good job in time banking, policy support is indispensable. At present, there is an unbreakable bottleneck in the bottom-up management mode of time banking, which can only be solved by the state. Although time bank has now been included into the national pilot reform of home-based community pension service by the Ministry of Civil Affairs of China and has drawn lots of attention, the support is relatively insufficient compared with that in foreign countries. In order to ensure the operation of time bank pension model, the British exempt taxes through a variety of policies, and the Japanese government provide subsidies to time bank, while China still stays in the pilot stage. The volunteer evaluation and incentive mechanism in China at present is still imperfect, which leads to the inadequate policy support for this mode. Under the emphasis on the "rule by law", only when the organs of state power formulate the corresponding laws to provide strong legal protection to the time bank pension service can it operate regularly on the basis of law.

\section{B. Difficulty in unifying the value of service}

"Time Bank" is not only the result of quantifying and materializing time but also the result of quantifying and materializing loving service. Edgar Kahn's idea of Time Bank was that all human labor was equal, that there was no distinction between high and low and that time is the only measure of value. However, it is unrealistic in perspective of public welfare. According to the current social and economic conditions and citizen quality in China, it is unpractical for citizens to launch public welfare activities spontaneously. Most of the people influence by Time Bank aim at getting paid from labor and saving money. But from compensatory, pricing is a problem needs to be solve. Because of the diversity of needs of the elderly, the same "time currency" differs from the difficulty and intensity. It is unfair and unreasonable to judge value only by working time. Therefore, the establishment of a perfect service exchange system and scientific measurement system is important to the development of "Time Bank".

\section{Social Awareness Is Inadequate}

To help time bank successfully develop in China, publicity is an essential step. However, social awareness of the time bank is remarkably inadequate. In 2013, the National Office on Aging conducted a nationwide survey on home-based care for the aged in 10 economically developed and aging cities including Beijing. According to the survey, up to $62.8 \%$ of the elderly know nothing about "time savings". The insufficient understanding lead to the struggling of time Banks, the difficulty in attracting people and the anxiety comes from the membership will also make it difficult to mobilize the participation of social groups.

\section{DEVELOPMENT COUNTERMEASURES OF TIME BANK PENSION MODEL}

Time bank pension model is a powerful method to actively deal with the aging problem and also, an important supplement to the traditional pension model. Support from multiple dimensions is needed for the development of this pension model.

\section{A. Strengthening policy support}

The absence of policy support makes Time Bank difficult to continue as it may be rebuffed, so it's important for the government to strengthen policy support in various aspects. First of all, the government should give the green light to the time bank pension in all aspects to provide it with a good living soil. Secondly, the local governments should support and standardize it through policies and laws. They should also give compensation to the pilots and call for the support of enterprise and the foundation. Only in this way can this model become standardized and develop steadily, which can also enhance the social credibility of the time bank pension model. To sum up, it is the government's urgent and unshakable responsibility to formulate policies, streamline the fund channel and remove the distrust.

\section{B. Unifying service standard}

Only with the unity of the service standard can time bank survive. Or psychological unbalance will cause a decline in membership enthusiasm which will lead to the collapse of the service system. It is difficult to set the standard for the value of the service. For example, if we take time for standard, then it is not suitable for Chinese society. So here two-way evaluation criteria is recommended. According to this criteria, the price of the "time currency" will be determined by the initiators and volunteers together and the platform will be a supervisor and a recorder. After all these, service initiators can give scores to the personnel according to their attitude and the degree of completion. If the service is satisfactory, then its credibility can be improved by the platform and also, the initiators can give more "time currency" as a reward. At the same time, if the work is too demanding to finish, servers can also complain to the platform. The problem will be solved by the platform. In this way, these three parties can be involved, which shows the fairness of this system. 


\section{Aggrandizing Propaganda}

The time bank pension mode is based on the joint efforts of the society which is mainly attracted by comprehensive and lasting propaganda. Old people have narrow access to new information so they may relatively out of style. They may not care about new media so the focus can be their sons and daughters, to whom accepting new media is easier. This may be more efficient if they talk to their parents about these new patterns. For example, leaflets can be distributed on campus or in enterprises, and advertisements can be pasted on public transportation. Young people's attention will be aroused in this way and with their acceptance ability, they can easily understand this pattern. While parents always trust their children's judgment and communication between them will be much more sufficient.

\section{CONCLUSION}

Under the adverse environment of poor physical and mental conditions of the elderly, lack of elderly care assistants and poor quality of elderly care services, China needs to deal with the issues of aging from multiple perspectives and aspects to meet diversified needs for elderly care. "The time bank" model, as a kind of new practical and operable endowment mode, has its unique advantages in playing a complementary role in building China's pension system. But seedlings thrive without hard water, we also need to provide it with room to grow from strengthening policy support and publicity and raising service standards, letting "the time bank" endowment patterns take root in China to contribute to China's aging population crisis.

\section{REFERENCES}

[1] Hang Wenchao, Yang Hualei. Development and Enlightenment of Time Bank Mutual Support for the Aged [J/OL].Southern Finance:1-11[2019-06-01].http://kns.cnki.net/kcms/detail/44.1479.F.201 90117.0931.002.html.

[2] Xi Jinping. Promoting comprehensive, coordinated and sustainable development of the cause of ageing [EB/OL]. (2016-05-29) [2018-06-26]. http://www.cncaprc.gov.cn/contents/2/174584.html.

[3] Liang Lei, Guo Fengying. Research and Practice on the model system of "time bank" pension platform [J]. Xinjiang Social Science, 2016 (3): $133-138+164$

[4] Hen Youhua, Shi Huanyin. Time Bank: Origin, Problems and Prospects [J]. Humanities Magazine 2015 (12): 111-118.

[5] Shi Wei. An Empirical Study on Time Savings of Old-age Care in Cities -Perspective of Social Participation of Old People [J]. Southern Population, 2014 (5): 58-68.

[6] Huang Haina. The Development Dilemma and Countermeasure of "Time Bank" Mutual Support for the Aged [J]. Journal of Culture, 2018 (3): 20-22. 